\title{
Measurement of serum estrogen and estrogen metabolites in pre- and postmenopausal women with osteoarthritis using high-performance liquid chromatography-electrospray ionization-tandem mass spectrometry
}

\author{
W.L. Gao ${ }^{1 *}$, L.S. Wu ${ }^{1 *}$, J.H. $\mathrm{Zi}^{1}$, B. Wu ${ }^{1}$, Y.Z. Li ${ }^{2}$, Y.C. Song ${ }^{3}$ and D.Z. Cai ${ }^{3}$ \\ ${ }^{1}$ Department of Orthopedics, Linyi People's Hospital of Shandong Province, Linyi, China \\ ${ }^{2}$ Guangdong Institute for Drug Control, Guangzhou, Guangdong, China \\ ${ }^{3}$ Department of Orthopedics, the Third Affiliated Hospital of Southern Medical University, Guangzhou, China
}

\begin{abstract}
Although $17 \beta$-estradiol $\left(E_{2}\right)$ deficiency has been linked to the development of osteoarthritis $(O A)$ in middle-aged women, there are few studies relating other estrogens and estrogen metabolites (EMs) to this condition. We developed a high-performance liquid chromatography-electrospray ionization-tandem mass spectrometry (HPLC-ESI-MS/MS) method to measure the levels of six EMs (i.e., estrone, $\mathrm{E}_{2}$, estriol, 2-hydroxyestrone, 2-hydroxyestradiol, and 16a-hydroxyestrone) in healthy pre- and postmenopausal women and women with $\mathrm{OA}$. This method had a precision ranging from 1.1 to $3.1 \%$ and a detection limit ranging from 10 to $15 \mathrm{pg}$. Compared to healthy women, serum-free $E_{2}$ was lower in the luteal and postmenopausal phases in women with $O A$, and total serum $E_{2}$ was lower in postmenopausal women with OA. Moreover, compared to healthy women, total serum 2-hydroxyestradiol was higher in postmenopausal women with OA and total serum 2-hydroxyestrone was lower in both the luteal and follicular phases in women with OA. In conclusion, our HPLC-ESI-MS/MS method allowed the measurement of multiple biochemical targets in a single assay, and, given its increased cost-effectiveness, simplicity, and speed relative to previous methods, this method is suitable for clinical studies.
\end{abstract}

Key words: Estrogen; Estrogen metabolites; Menopause; Serum; Osteoathritis

\section{Introduction}

Estrogens are endogenous female hormones required for the growth and development of target tissues, including the mammary gland, and which play a major role in the etiology of breast cancer $(1,2)$. Estrogen metabolism has been related to osteoporosis and increased fracture risk $(3,4)$, and lower baseline serum $17 \beta$-estradiol $\left(E_{2}\right)$ and urinary 2-hydroxyestrone $\left(2-\mathrm{OHE}_{1}\right)$ levels have been linked to knee osteoarthritis $(\mathrm{OA})$ in middle-aged women (5). That said, there are relatively few studies linking serum levels of other estrogens and estrogen metabolites (EMs) to the pathogenesis of female OA.

Endogenous estrones $\left(E_{1}\right)$ and $E_{2}$ are synthesized from the androgenic precursors androstenedione and testosterone, respectively, in a reaction catalyzed by cytochrome P450 aromatase, which is expressed primarily in ovarian granulosa cells, adipose stromal cells, and the placenta. Circulating $E_{2}$, the primary estrogen in premenopausal and early perimenopausal women, declines with menopause. $E_{1}$ generated by oxidation of $E_{2}$ is hydroxylated via two mutually exclusive pathways (6) to generate either 2-hydroxyestrone (2-OHE 1 ) or 16a-hydroxyestrone (16a-OHE ${ }_{1}$; Figure 1), which are estrogen agonists (7) with target tissue-specific biological activities distinct from one another and from $E_{2}$. Compared to $E_{2}, 16 a-O H E_{1}$ binds with lower affinity to both the estrogen receptor (8) and to serum sex hormone-binding globulin, and is consequently

Correspondence: Wanli Gao: <gaowanli1977@163.com>.

${ }^{*}$ These authors contributed equally to this study.

Received May 15, 2014. Accepted September 9, 2014. First published online November 14, 2014. 


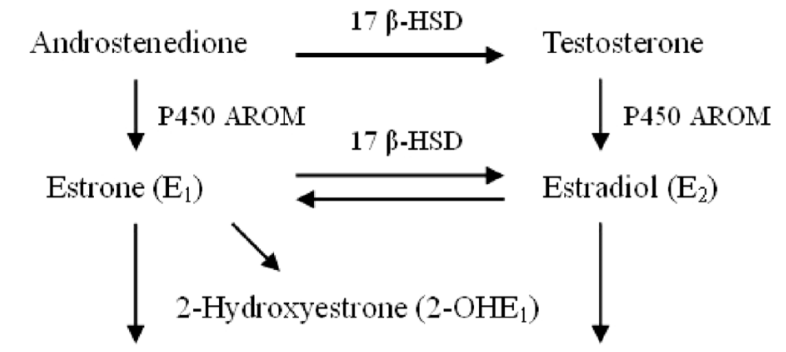

16a-Hydroxyestrone $\rightarrow$ Estriol 2-Hydroxyestradiol
$(16 \mathrm{a}-\mathrm{OHE})$
$\left(\mathrm{E}_{3}\right)$
$\left(2-\mathrm{OHE}_{2}\right)$

Figure 1. Estrogen metabolism pathways, including estrone, estradiol, and estrogen metabolites. 17 $\beta$-HSD: 17beta-hydroxysteroid dehydrogenase; P450 AROM: cytochrome P450 aromatase.

more available in estrogen-sensitive target tissues than $E_{2}$. Although 2-hydroxyestrogens have a reduced binding affinity for the estrogen receptor compared to $16 \mathrm{a}-\mathrm{OHE}_{1}$, they participate in oxidation/reduction reactions $(9,10)$.

A variety of analytical methods have been developed to analyze EMs, including spectrophotometry (11) and thin-layer chromatography (12) for high EM levels, and radioimmunoassay (RIA) $(13,14)$ and enzyme-linked immunosorbent assay (15) for trace EM levels. Given the problems of cross-contamination associated with these techniques, however, gas chromatography (GC) (16) and high-performance liquid chromatography (HPLC) $(17,18)$ are typically used to detect ingredients in Chinese formulated products because of their outstanding separation power and automatable nature. However, owing to the presence of multiple components in blood samples, EMs cannot be readily quantified using GC and HPLC, which discriminate by retention time only.

HPLC-electrospray ionization-tandem mass spectrometry (HPLC-ESI-MS/MS) offers a variety of advantages over these methods for the quantification of serum EMs.
Chromatographic separation removes most of the interferences caused by impurities, and multiple co-eluting moieties with distinct molecular masses and chemical structures generate characteristic fragments and specific mass spectra. Although LC/MS methods (19-21) measure more biochemical targets in a single assay than HPLC-ESI-MS/ MS, the multiple reaction-monitoring quantitative model of HPLC-ESI-MS/MS allows the identification and quantification of products in the picogram range in only $10 \mathrm{~mL}$ of blood. We established an HPLC-ESI-MS/MS method to determine serum levels of 6 EMs in pre- and postmenopausal women with OA and in healthy women (Figure 2).

\section{Material and Methods}

\section{Equipment}

The following equipment was used: $\mathrm{Tl}-\mathrm{H}-15$ supersonic generator (ELMA, Germany), incubator (LRH-250A, Guangdong Province Medical Instrument Factory, China), LABORTA 4003 rotary evaporation (Heidolphon, Germany), U3 aqueous bath (Julabo, Germany), LRH-250A homeothermia incubator (Medical Apparatus and Instruments Factory, China), Mili- $Q$ deionized water deviser (Millipore, USA), ME-5 electronic balance (Sartorius, Germany), API3000 tandem quadrupole axle mass spectrometer (AB Company, USA), and an Agilent 1100 liquid chromatography system (Agilent, USA), ZORBAX C18 chromatographic column $(4.6 \times 250$ mm, $5 \mu \mathrm{m}$; SN: USCN004202; Agilent).

\section{Reagents}

Chlormycetin, glucuronidase, and aryl vitriol acetum enzyme were obtained from Sigma Chemical Co. (USA). All selected EMs and chlormycetin had chemical purity $\geq 98 \%$ and were applied without further purification. Methanol, acetonitrile, toluene (chromatographic-grade purity), glucuronidase/aryl vitriol acetum enzyme solution, ammonium acetate, acetic acid, methyl tertiary butyl ether (MTBE), and acetidin were obtained from Merck \& Co., Inc. (USA).

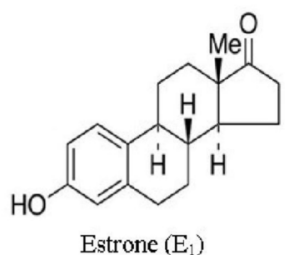

MF $\mathrm{C}_{18} \mathrm{H}_{22} \mathrm{O}_{2}$ MM 270.37

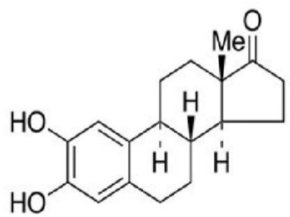

2-Hydroxyestrone (2- $\left.\mathrm{OH}_{1}\right)$ MF $\mathrm{C}_{18} \mathrm{H}_{22} \mathrm{O}_{3} \mathrm{MM} 286.37$

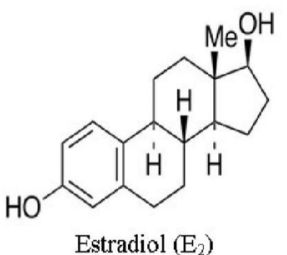

MF $\mathrm{C}_{18} \mathrm{H}_{24} \mathrm{O}_{2}$ MM 272.38

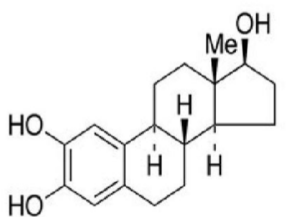

2-Hydroxyestradiol (2- $\left.\mathrm{OHE}_{2}\right)$ MF $\mathrm{C}_{18} \mathrm{H}_{24} \mathrm{O}_{3} \mathrm{MM} 288.38$

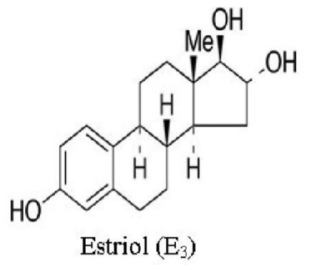

MF $\mathrm{C}_{18} \mathrm{H}_{24} \mathrm{O}_{3}$ MM 288.38

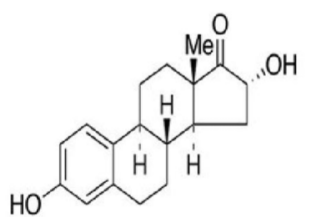

$16 \mathrm{a}-\mathrm{Hydroxyestrone}\left(16 \mathrm{a}-\mathrm{OH}_{\mathrm{l}}\right)$ $\mathrm{MF} \mathrm{C}_{18} \mathrm{H}_{22} \mathrm{O}_{3} \mathrm{MM} 286.37$
Figure 2. Chemical structure, molecular formula (MF), and molecular mass (MM) of the 6 estrogen metabolites. 


\section{Preparation of standard solutions}

Stock solutions of 6 EMs (Figure 2) and chlormycetin were each prepared at $80 \mu \mathrm{g} / \mathrm{mL}$ by dissolving $2 \mathrm{mg}$ of each EM or chlormycetin powder in methanol to a final volume of $25 \mathrm{~mL}$ in a volumetric flask. Stock solutions were monitored for time-dependent degradation by measuring the absolute peak height of each EM and chlormycetin. The stock solutions were stable for at least 50 days if stored at $-20^{\circ} \mathrm{C}$. Standard solutions were prepared by diluting $1.0 \mathrm{~mL}$ of each EM stock solution in methanol to a final volume of $100 \mathrm{~mL}$.

Calibration standards $(1,5,10,20,40$, and $80 \mathrm{ng} / \mathrm{mL})$ were prepared by diluting standard solutions in methanol. Internal standard solutions were prepared by diluting $0.25 \mathrm{~mL}$ of chlormycetin stock standard solution in methanol to a final volume of $20 \mathrm{~mL}$.

\section{Acetate buffer solution preparation}

Acetate buffer solution at $0.04 \mathrm{M}$ was prepared by dissolving $43.0 \mathrm{~g}$ ammonium acetate in $200 \mathrm{~mL}$ water, and then adding $25.2 \mathrm{~g}$ glacial acetic acid. The $\mathrm{pH}$ was adjusted to 5.0 and the final volume was brought to $1000 \mathrm{~mL}$ using water.

\section{Subjects}

All subjects were Asian. Baseline characteristics included age, disease duration, body height, body weight, and body mass index (Table 1). Thirty-two premenopausal outpatients (aged 37-47 years) and 32 postmenopausal inpatients (aged 55-68 years) with OA of the knee were selected as the experimental groups, and 48 healthy women, including 24 premenopausal women (aged 37-46 years) and 24 postmenopausal women (aged 56-69 years), participated as the control group. The length of time since menopause in all experimental and control postmenopausal women was in excess of 5 years. All patients were from the Linyi People's Hospital (Shandong, China). OA patients were from the Orthopedics Department, and healthy controls were from the Medical Examination Center. All subjects gave written informed consent and the study was approved by the Institute Ethics Committee of Linyi People's Hospital.

Patients reporting knee pain and stiffness (time $<30 \mathrm{~min}$ ) or crepitus were diagnosed as symptomatic OA if a definite osteophyte was observed in the symptomatic knee on plain radiographs, in accordance with American College of Rheumatology criteria for OA (22). Exclusion criteria for patients included: nonsteroidal anti-inflammatory drugs 3 days prior to the investigation; corticosteroid therapy during the 6 months prior to the investigation; use of contraceptives, weight-reducing aids, vitamin $D$, or any hormone-replacement therapy; recent history of medication, malignancy, hypertension, diabetes, viral hepatitis, parenchyma liver diseases, or fatty liver. Exclusion criteria for healthy pre- or postmenopausal women included a history of OA, smoking and alcohol use, and current pregnancy.

\section{Blood sample collection}

Venous blood was collected from premenopausal and postmenopausal OA patients and healthy women. In premenopausal subjects, blood samples were collected during the follicular (days 5-7) and luteal (days 22-25) phases of the same menstrual cycle, whereas only one blood sample was drawn from postmenopausal subjects. Menstrual and menopausal status was self-reported. Menopausal status was defined as premenopausal (women having regular menses) or postmenopausal (no menses in the last 12 months). Blood was allowed to clot for $1 \mathrm{~h}$ at room temperature, then centrifuged at $300 \mathrm{~g}$ for $10 \mathrm{~min}$ and frozen at $-80^{\circ} \mathrm{C}$ until assayed.

\section{Sample preparation procedure}

Internal standard solutions $(50 \mu \mathrm{L})$ were added to a 0.5 $\mathrm{mL}$ aliquot of serum, after which $100 \mu \mathrm{L}$ freshly prepared glucuronidase/sulfatase and $2.0 \mathrm{~mL} 0.04 \mathrm{M}$ acetate buffer solutions were added. After vortexing, the sample was transferred to an incubator and hydrolyzed at $37^{\circ} \mathrm{C}$ for $4-8 \mathrm{~h}$. After hydrolysis, $5 \mathrm{~mL}$ acetidin was added to the mixture, which was then placed in the supersonic generator for $5 \mathrm{~min}$. After centrifuging at $12,000 \mathrm{~g}$ for $10 \mathrm{~min}$, the supernatant (organic liquid phase) was transferred to a rotary evaporation bottle, and the remaining solution was extracted with acetidin. The supernatant was then mixed and evaporated to dryness in a rotary evaporation apparatus at $40^{\circ} \mathrm{C}$, after which $0.5 \mathrm{~mL}$ methanol was added to dissolve the extract. Samples were analyzed by HPLC-ESI-MS/MS after $0.45-\mu \mathrm{m}$ filtering (Millipore). Samples for free serum

Table 1. Baseline characteristics of subjects.

\begin{tabular}{|c|c|c|c|c|c|c|}
\hline & \multicolumn{2}{|c|}{ Follicular phase } & \multicolumn{2}{|c|}{ Luteal phase } & \multicolumn{2}{|c|}{ Postmenopausal phase } \\
\hline & $\mathrm{OA}(\mathrm{n}=32)$ & Control $(n=24)$ & $O A(n=32)$ & Control $(n=24)$ & $\mathrm{OA}(\mathrm{n}=32)$ & Control $(n=32)$ \\
\hline Age (years) & $41.8 \pm 5.7$ & $43.4 \pm 7.4$ & $41.8 \pm 5.7$ & $43.4 \pm 7.4$ & $60.6 \pm 6.4$ & $56.9 \pm 3.0$ \\
\hline Disease duration & $4.6 \pm 2.0$ & NA & $4.6 \pm 2.0$ & NA & $16.3 \pm 2.2$ & NA \\
\hline Body height (cm) & $156.2 \pm 0.7$ & $151.2 \pm 0.6$ & $156.2 \pm 0.7$ & $151.2 \pm 0.6$ & $154.8 \pm 0.6$ & $159.1 \pm 0.8$ \\
\hline Body weight (kg) & $59.2 \pm 5.4$ & $56.7 \pm 6.4$ & $59.2 \pm 5.4$ & $56.7 \pm 6.4$ & $71.5 \pm 4.9$ & $69.1 \pm 6.5$ \\
\hline $\operatorname{BMI}\left(\mathrm{kg} / \mathrm{m}^{2}\right)$ & $24.2 \pm 1.7$ & $23.0 \pm 1.8$ & $24.2 \pm 1.7$ & $23.0 \pm 1.8$ & $30.5 \pm 1.4$ & $27.6 \pm 3.4$ \\
\hline
\end{tabular}

Data are reported as means \pm SD. OA: osteoarthritis; control: healthy women; BMI: body mass index; NA: not applicable. 
Table 2. Mass spectrometry parameters of HPLC-ESI-MS/MS measurements of estrogen metabolites and chlormycetin.

\begin{tabular}{lcrcccc}
\hline & Q1/Q3 & DP & FP & EP & CE & CXP \\
\hline $\mathrm{E}_{1}$ & $269 / 145$ & 121 & 219 & 11 & 50 & 34 \\
$\mathrm{E}_{2}$ & $271 / 183$ & 30 & 200 & 10 & 55 & 15 \\
$\mathrm{E}_{3}$ & $287 / 145$ & 121 & 350 & 10 & 60 & 21 \\
$2-\mathrm{OHE}_{1}$ & $285 / 160$ & 121 & 219 & 11 & 52 & 15 \\
$2-\mathrm{OHE}_{2}$ & $287 / 147$ & 121 & 219 & 11 & 60 & 15 \\
16a-OHE $_{1}$ & $285 / 145$ & 85 & 350 & 10 & 54 & 23 \\
Chlormycetin & $320 / 257$ & 30 & 300 & 10 & 21 & 15 \\
\hline
\end{tabular}

Q1/Q3: parent ion/daughter ion; DP: declustering potential; FP: focusing potential; EP: entrance potential; CE: collision energy; CXP: collision cell exit potential. $\mathrm{E}_{1}$ : estrone; $\mathrm{E}_{2}$ : estradiol; $\mathrm{E}_{3}$ : estriol; 2-OHE 1 : 2-hydroxyestrone; 2-OHE 2 : 2-hydroxyestradiol; 16a-OHE 1 : 16a-hydroxyestrone.
EM measurement were processed as described earlier, with the exclusion of the glucuronidase/sulfatase hydrolysis step.

\section{Calibration standards preprocessing}

Internal standard solutions $(50 \mu \mathrm{L})$ were added to each of the calibration standards $(1,5,10,20,40$, and $80 \mathrm{ng} / \mathrm{mL})$, following the addition of $100 \mu \mathrm{L}$ freshly prepared glucuronidase/sulfatase and $2.0 \mathrm{~mL} 0.04-\mathrm{M}$ acetate buffer solution. After vortexing, the samples were transferred to an incubator at $37^{\circ} \mathrm{C}$ for $4 \mathrm{~h}$.

\section{HPLC-ESI-MS/MS analysis}

HPLC-ESI-MS/MS analysis was performed using an API3000 tandem quadrupole axle mass spectrometer with a Turbo spray ESI ionization source. Data were processed using an Analyst 1.4 workstation. HPLC samples (10 $\mu \mathrm{L})$ were injected on a ZORBAX C18 chromatographic column,
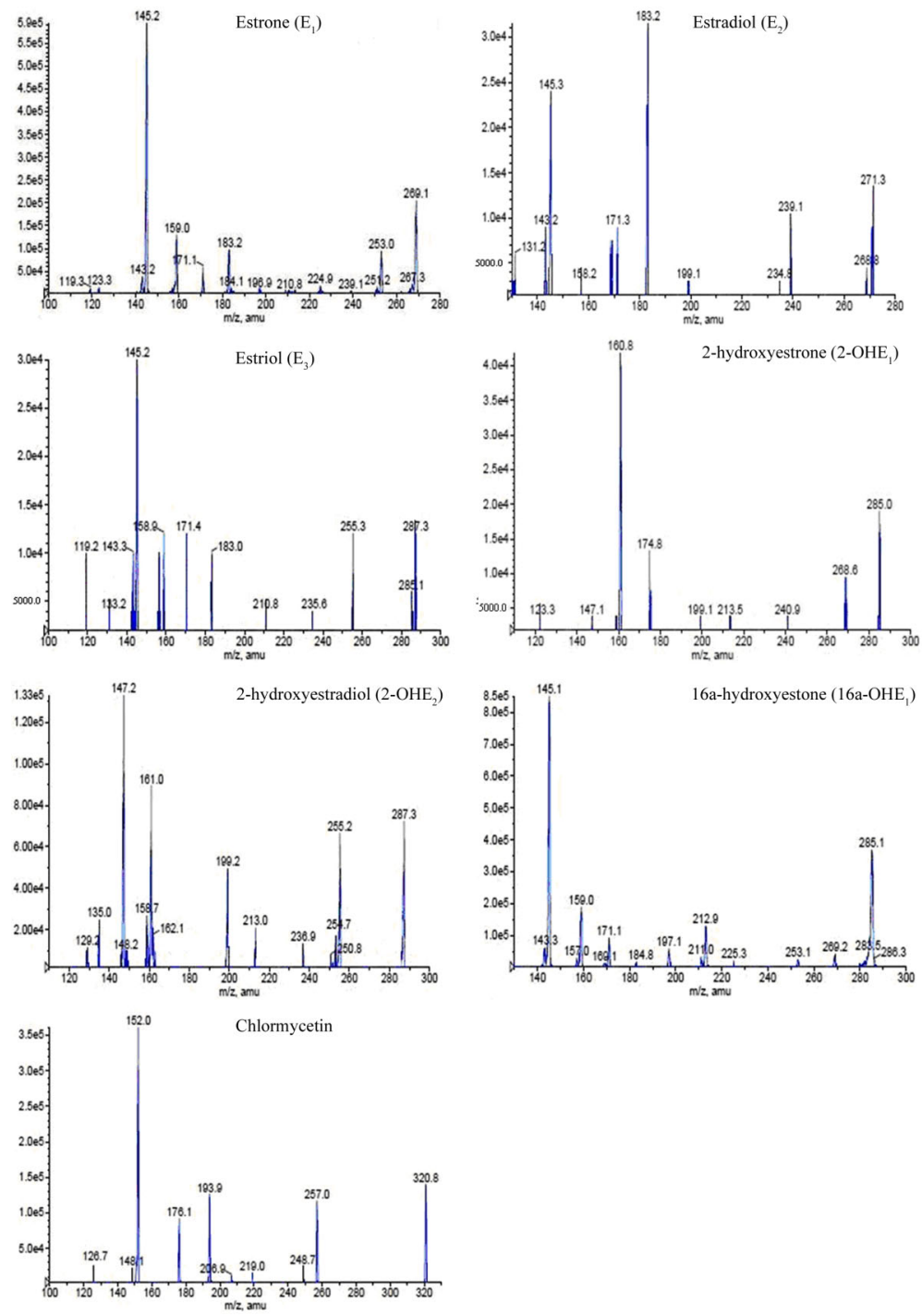

Figure 3. Product mass spectrum of EMs and internal standards. $\mathrm{E}_{1}$ : estrone; $\mathrm{E}_{2}$ : estradiol; $\mathrm{E}_{3}$ : estriol; 2-OHE 1 : 2-hydroxyestrone; 2-OHE 2 : 2hydroxyestradiol; 16a-OHE 1 : 16a-hydroxyestrone; chlormycetin. 


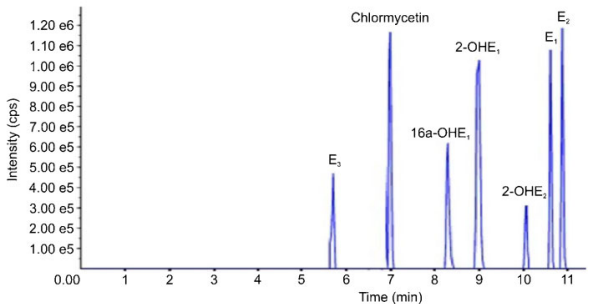

Figure 4. Total ion flow chart. $E_{1}$ : estrone; $E_{2}$ : estradiol; $E_{3}$ : estriol; 2- $\mathrm{OHE}_{1}$ : 2-hydroxyestrone; 2-OHE 2 : 2-hydroxyestradiol; 16a-OHE ${ }_{1}$ : 16a-hydroxyestrone.

and maintained at $35^{\circ} \mathrm{C}$. The mobile phase consisted of methyl cyanide solution and operated at a flow rate of $200 \mu \mathrm{L} / \mathrm{min}$. For the analysis of EMs, a linear gradient was established that changed the methyl cyanide/water solvent ratio from 20/7 to 20/13 over $15 \mathrm{~min}$. The ionizing voltage was $-4200 \mathrm{~V}$ in the negative ion mode, the ion pair of the parent ion (Q1)/daughter ion (Q3) was set up as the unit of discernment, and the dwell time of each ion pair was $150 \mathrm{~ms}$. Other parameters are listed in Table 2.

\section{Statistical analysis}

Normal distributions were validated using the Kolmogorov-Smirnov method. Intergroup comparisons were carried out using an independent-samples $t$-test to determine whether experimental and control values in $\mathrm{OA}$ and healthy women were significantly different. All statistical analyses were performed using the SPSS software (USA). Type I error was assessed based on two-sided tests. $P$ values less than 0.05 were considered to be significant.

\section{Results}

\section{Characteristic ion pair options of MS/MS}

For the phenolic hydroxyl group of estrogens as proton donors, the signal is known to be more sensitive in the negative ion mode than in the positive ion mode. In this study, an exteriorized needle pump mode was used for each standard solution of $\mathrm{E}_{1}, \mathrm{E}_{2}, \mathrm{E}_{3}, 2-\mathrm{OHE}_{1}, 2-\mathrm{OHE}_{2}$,
16a-OHE ${ }_{1}$, or chlormycetin. In negative ion mode, mass spectra were typical and specific for each reference substance (Figure 3).

\section{Selection of color spectrum behavior and diagnosis ions}

The most sensitive and characteristic parent ion and daughter ion of each reference substance were selected to compose an ion pair, which were then measured after separating with methyl cyanide solution. We found that a fixed-proportion mobile phase was unsuitable for quantitative analysis because it failed to separate the 6 EM reference substances effectively owing to the width of the chromatographic peaks. We subsequently established chromatographic conditions in which each reference substance was completely separated with satisfactory signal intensity (Figure 4).

\section{Selection of extraction solvent}

We tested the extraction efficiency of alcohol, acetone, ethylether, acetidin, MTBE, and chloroform with respect to the selected EMs and chlormycetin, and found that MTBE was the most efficient (data not shown).

\section{Methodology index analysis}

The precision, recovery, and other methodology indices for each ion pair are listed in Table 3. The detection limit was defined as the concentration corresponding to a level 10 times above the level of acoustic noise when a blank sample was added to each progressively diluted reference substance solution. Precision was measured from the relative standard deviation of the mean of 11 continuous measurements after adding $1.0 \mathrm{ng}$ internal standard to each sample. Accuracy was defined as the mean value of each sample of 20 replicates with known concentrations, in which $1.0 \mathrm{ng}$ internal standard was added. Recovery was calculated using the formula: $P(\%)=\left(C_{a l l}-C_{\text {sample }}\right) / C_{\text {addition }} \times 100$.

\section{Serum levels of selected estrogens and estrogen metabolites}

Compared to healthy women, serum-free $E_{2}$ was lower $(\mathrm{P}<0.05)$ in the luteal and postmenopausal phases

Table 3. Methodology index of estrogen metabolite analyses.

\begin{tabular}{lcccrrr}
\hline & $\begin{array}{c}\text { Linear range } \\
(\mathrm{ng} / \mathrm{mL})\end{array}$ & Linear equation & $r$ & Precision (\%) & $\begin{array}{r}\text { Recovery (\%) } \\
\text { Detection limit } \\
(\mathrm{pg})\end{array}$ \\
\hline $\mathrm{E}_{1}$ & $0.2-10000$ & $\mathrm{y}=0.01126 \mathrm{x}-0.01701$ & 0.9994 & 2.6 & 98.8 & 10 \\
$\mathrm{E}_{2}$ & $0.2-10000$ & $\mathrm{y}=0.00778 \mathrm{x}+0.00104$ & 0.9998 & 1.3 & 103.4 & 10 \\
$\mathrm{E}_{3}$ & $0.7-10000$ & $\mathrm{y}=0.00434 \mathrm{x}-0.00229$ & 0.9997 & 2.1 & 97.6 & 15 \\
$2-\mathrm{OHE}_{1}$ & $1.0-10000$ & $\mathrm{y}=0.00835 \mathrm{x}+0.03071$ & 0.9995 & 1.8 & 107.4 & 10 \\
$2-\mathrm{OHE}_{2}$ & $0.5-10000$ & $\mathrm{y}=0.00634 \mathrm{x}+0.03022$ & 0.9999 & 1.1 & 99.4 & 15 \\
$16 \mathrm{a}-\mathrm{OHE}$ & $0.2-10000$ & $\mathrm{y}=0.001132 \mathrm{x}+0.02173$ & 0.9991 & 3.1 & 105.4 & 10 \\
\hline
\end{tabular}

r: correlation coefficient; $\mathrm{E}_{1}$ : estrone; $\mathrm{E}_{2}$ : estradiol; $\mathrm{E}_{3}$ : estriol; 2-OHE $\mathrm{E}_{1}$ : 2-hydroxyestrone; 2-OHE 2 : 2-hydroxyestradiol; 16a-OHE 1 : 16ahydroxyestrone. 
Table 4. Serum free (unconjugated) and total (conjugated + unconjugated) levels of selected estrogen metabolites in the follicular, luteal, and postmenopausal phases in women with OA and healthy controls.

\begin{tabular}{|c|c|c|c|c|c|c|}
\hline & \multicolumn{2}{|c|}{ Follicular phase } & \multicolumn{2}{|c|}{ Luteal phase } & \multicolumn{2}{|c|}{ Postmenopausal phase } \\
\hline & $\mathrm{OA}(\mathrm{n}=32)$ & Control $(n=24)$ & $\mathrm{OA}(\mathrm{n}=32)$ & Control $(n=24)$ & OA $(n=32)$ & Control $(n=24)$ \\
\hline \multicolumn{7}{|l|}{ Free } \\
\hline$E_{1}$ & $52.5 \pm 21.7$ & $54.1 \pm 11.9$ & $48.0 \pm 6.6$ & $51.3 \pm 2.7$ & $28.2 \pm 9.4$ & $31.9 \pm 4.8$ \\
\hline $\mathrm{E}_{2}$ & $71.5 \pm 14.2$ & $75.1 \pm 19.1$ & $65.0 \pm 9.2^{*}$ & $72.3 \pm 3.2$ & $13.7 \pm 3.1^{*}$ & $18.2 \pm 5.6$ \\
\hline $\mathrm{E}_{3}$ & $15.4 \pm 4.8$ & $14.7 \pm 1.8$ & $16.6 \pm 2.0$ & $17.4 \pm 1.4$ & $5.9 \pm 1.4$ & $7.0 \pm 1.1$ \\
\hline \multicolumn{7}{|l|}{ Total } \\
\hline $\mathrm{E}_{1}$ & $643.0 \pm 310.5$ & $670.9 \pm 113.4$ & $726.6 \pm 42.0$ & $756.5 \pm 68.8$ & $404.1 \pm 62.5$ & $426.6 \pm 34.7$ \\
\hline$E_{2}$ & $117.9 \pm 14.5$ & $123.8 \pm 28.8$ & $141.5 \pm 9.3$ & $149.4 \pm 18.5$ & $40.1 \pm 8.0^{* *}$ & $51.4 \pm 12.1$ \\
\hline $\mathrm{E}_{3}$ & $48.0 \pm 18.2$ & $51.8 \pm 11.6$ & $49.5 \pm 7.0$ & $47.0 \pm 6.2$ & $24.7 \pm 8.0$ & $27.0 \pm 5.9$ \\
\hline $2-\mathrm{OHE}_{1}$ & $262.7 \pm 45.4^{*}$ & $304.1 \pm 51.5$ & $264.2 \pm 40.4^{*}$ & $296.5 \pm 31.1$ & $64.1 \pm 9.2$ & $67.3 \pm 8.4$ \\
\hline $2-\mathrm{OHE}_{2}$ & $27.1 \pm 7.9$ & $24.0 \pm 7.8$ & $26.3 \pm 8.4$ & $23.9 \pm 7.2$ & $16.9 \pm 4.9^{* *}$ & $11.6 \pm 4.0$ \\
\hline $16 a-O H E_{1}$ & $23.1 \pm 5.3$ & $25.4 \pm 6.7$ & $22.1 \pm 2.3$ & $23.4 \pm 1.6$ & $11.6 \pm 2.0$ & $13.1 \pm 1.2$ \\
\hline
\end{tabular}

Data are reported as means $\pm S D$ in $\mathrm{pg} / \mathrm{mL}$. OA: osteoarthritis; control: healthy women; $\mathrm{E}_{1}$ : estrone; $\mathrm{E}_{2}$ : estradiol; $\mathrm{E}_{3}$ : estriol; 2-OHE : 2-hydroxyestrone; 2- $\mathrm{OHE}_{2}$ : 2-hydroxyestradiol; 16a- $\mathrm{OHE}_{1}$ : 16a-hydroxyestrone. ${ }^{*} \mathrm{P}<0.05, \mathrm{OA}$ compared to control; ${ }^{* *} \mathrm{P}<0.01, \mathrm{OA}$ compared to control (t-test).

in women with $\mathrm{OA}$, and total serum $\mathrm{E}_{2}$ was lower $(\mathrm{P}<0.01)$ in postmenopausal women with OA (Table 4). Furthermore, compared to healthy women, total serum 2$\mathrm{OHE}_{2}$ was higher $(\mathrm{P}<0.01)$ in postmenopausal women with $\mathrm{OA}$ and total serum $2-\mathrm{OHE}_{1}$ was lower $(\mathrm{P}<0.05)$ in both the luteal and follicular phases in women with $O A$. Neither free nor total serum levels of $E_{1}$ and $E_{3}$ in pre- and postmenopausal women with OA differed significantly from those in healthy subjects.

\section{Discussion}

OA involves the progressive degeneration of articular cartilage and structural changes in the underlying bone, including the development of marginal growths and osteophytes, and thickening of the periosteum (23). A century ago, the description by Cecil and Archer (24) of "arthritis of the menopause," referring to the development of hand and knee OA during menopause, suggested that estrogen deficiency might play a role in OA. Subsequent epidemiological studies have indicated that the incidence and prevalence of hip, knee, and finger OA are greater in men than in women before 50 years of age, after which age they are increasingly more common in women compared to men (25).

The expression of estrogen receptors in articular cartilage (26) suggests that, in addition to estradiol deficiency, $2-\mathrm{OHE}_{1}$ and $2-\mathrm{OHE}_{2}$ might be involved in the etiology of female $O A$ and that manipulation of their levels has potential in the prevention and cure of this condition. In this regard, future studies are required to determine the specific cell types, such as chondrocytes, synoviocytes, and bone cells, that are involved in reducing levels of $17 \beta$-estradiol $\left(E_{2}\right)$ and
$2-\mathrm{OHE}_{1}$, and in raising levels of 2-OHE 2 .

Our HPLC-ESI-MS/MS assay had a detection limit of 10$15 \mathrm{pg} / \mathrm{mL}$ serum and a precision of $1.1-3.1 \%$, enabling us to measure endogenous serum estrogens in pre- and postmenopausal women. The identification and quantification of serum estradiol levels in the low pre- and postmenopausal range $(<30 \mathrm{pg} / \mathrm{mL})$ are important prognostic tools for common chronic diseases of women (27). RIA methods are insufficiently accurate or sensitive to monitor serum estradiol at such low levels (28-30), and, although bioassays using recombinant yeast and HeLa cells are more sensitive than RIA, they lack specificity and convenience (31). Moreover, whereas $\mathrm{GC} /$ tandem mass spectrometry is sufficiently specific, sensitive, and accurate, it lacks the precision of our HPLC-ESI-MS/MS method (32-34). The MS-based detection of derivatized estrogens in multiple samples using the cation mode of analysis has been recently reported (35). Although this approach reportedly raised the sensitivity of analysis, the efficiency of derivation was not investigated in a previous study (36), suggesting that the derivation procedure might introduce errors. In addition, the isotope-labeled estrogens and EM standards used in previous studies $(22,37,38)$ are more expensive than our negative ion mode MS/MS assay.

The free serum $E_{2}$ levels in pre- and postmenopausal women detected in the current study (Table 4) were statistically similar to those obtained previously (23), with four-fold lower standard deviations and a six-fold greater number of samples from postmenopausal women.

In conclusion, we have established an HPLC-ESI-MS/ MS method for the simultaneous detection of serum levels of 6 EMs in pre- and postmenopausal women with OA and healthy controls. Because the MS/MS was performed 
in multiple reaction-monitoring tandem quadrupole mass spectrometry using ESI in negative ion mode, blood samples derivatives were not necessary, making the assay more economical, rapid, and efficient. Accordingly, our HPLC-ESI-MS/MS method has potential clinical applications, as well as for treatment or intervention studies requiring precise measurements of fluctuations in EM levels, such as in perimenopausal women, or measurement of low analyte concentrations. In this regard, further improvements are required to minimize variability in measurements.

\section{References}

1. Henderson BE, Feigelson HS. Hormonal carcinogenesis. Carcinogenesis 2000; 21: 427-433, doi: 10.1093/carcin/21.3. 427.

2. Cavalieri E, Chakravarti D, Guttenplan J, Hart E, Ingle J, Jankowiak R, et al. Catechol estrogen quinones as initiators of breast and other human cancers: implications for biomarkers of susceptibility and cancer prevention. Biochim Biophys Acta 2006; 1766: 63-78

3. Lim SK, Won YJ, Lee JH, Kwon SH, Lee EJ, Kim KR, et al. Altered hydroxylation of estrogen in patients with postmenopausal osteopenia. J Clin Endocrinol Metab 1997; 82: 10011006, doi: 10.1210/jcem.82.4.3875.

4. Hodge J, Roodman-Weiss J, Lyss C, Wagner D, Klug T, Civitelli R. Increased inactive estrogen metabolites in urine of early postmenopausal women with low bone density. J Bone Miner Res 1995; 10: S444.

5. Sowers MR, McConnell D, Jannausch M, Buyuktur AG, Hochberg M, Jamadar DA. Estradiol and its metabolites and their association with knee osteoarthritis. Arthritis Rheum 2006; 54: 2481-2487, doi: 10.1002/art.22005.

6. Fishman J. Aromatic hydroxylation of estrogens. Annu Rev Physiol 1983; 45: 61-72, doi: 10.1146/annurev.ph.45.030183. 000425.

7. Lotinun S, Westerlind KC, Turner RT. Tissue-selective effects of continuous release of 2-hydroxyestrone and 16alphahydroxyestrone on bone, uterus and mammary gland in ovariectomized growing rats. J Endocrinol 2001; 170: 165174, doi: 10.1677/joe.0.1700165.

8. Robinson JA, Waters KM, Turner RT, Spelsberg TC. Direct action of naturally occurring estrogen metabolites on human osteoblastic cells. J Bone Miner Res 2000; 15: 499-506, doi: 10.1359/jbmr.2000.15.3.499.

9. MacLusky NJ, Riskalla M, Krey L, Parvizi N, Naftolin F. Anovulation in female rats induced by neonatal administration of the catechol estrogens, 2-hydroxy-estradiol and 4hydroxy-estradiol. Neuroendocrinology 1983; 37: 321-327, doi: 10.1159/000123569.

10. Tang M, Abplanalp W, Ayres S, Subbiah MT. Superior and distinct antioxidant effects of selected estrogen metabolites on lipid peroxidation. Metabolism 1996; 45: 411-414, doi: 10.1016/S0026-0495(96)90212-7

11. Szabo A. [A technic for the determination of ethinyl estradiol and norgestrel]. Acta Pharm Hung 1977; 47: 24-28.

12. Stan HJ, Hohls FW. [Detection of estrogen residues in meat by thin layer chromatography and fluorimetry (author's transl)]. Z Lebensm Unters Forsch 1978; 166: 287-292,

\section{Acknowledgments}

Research supported by the Excellent Young Scientist Research Award fund of Shandong China (\#BS2011YY040), the Medical and Health Science and Technology Development Plan of Shandong China (\#2011QW009), and the development projects of Shandong Province Science and Technology of Traditional Chinese Medicine (\#2013ZDZK155).

doi: $10.1007 / B F 01127655$

13. Numazawa $M$, Kimura $K$, Nagaoka $M$, Kambegawa $A$. Radioimmunoassay of 2-hydroxyesterone using antisera raised against antigenic complexes obtained by convenient methods. Chem Pharm Bull 1989; 37: 1561-1563, doi 10.1248/cpb.37.1561.

14. McGuinness BJ, Power MJ, Fottrell PF. Radioimmunoassay of 2-hydroxyestrone in urine. Clin Chem 1994; 40: 80-85.

15. Bradlow HL, Sepkovic DW, Klug T, Osborne MP. Application of an improved ELISA assay to the analysis of urinary estrogen metabolites. Steroids 1998; 63: 406-413, doi: 10.1016/S0039-128X(98)00041-5.

16. Adlercreutz $\mathrm{H}$, Tikkanen MJ, Hunneman DH. Mass fragmentographic determination of eleven estrogens in the body fluids of pregnant and nonpregnant subjects. J Steroid Biochem 1974; 5: 211-217, doi: 10.1016/0022-4731(74)90134-4.

17. Higashi T, Takayama N, Nishio T, Taniguchi E, Shimada K. Procedure for increasing the detection responses of estrogens in LC-MS based on introduction of a nitrobenzene moiety followed by electron capture atmospheric pressure chemical ionization. Anal Bioanal Chem 2006; 386: 658-665, doi: 10.1007/s00216-006-0371-z.

18. Xu X, Roman JM, Issaq HJ, Keefer LK, Veenstra TD, Ziegler RG. Quantitative measurement of endogenous estrogens and estrogen metabolites in human serum by liquid chromatography-tandem mass spectrometry. Anal Chem 2007; 79 : 7813-7821, doi: 10.1021/ac070494j.

19. Rothman MS, Carlson NE, Xu M, Wang C, Swerdloff R, Lee $P$, et al. Reexamination of testosterone, dihydrotestosterone, estradiol and estrone levels across the menstrual cycle and in postmenopausal women measured by liquid chromatography-tandem mass spectrometry. Steroids 2011; 76 177-182, doi: 10.1016/j.steroids.2010.10.010.

20. Carvalho VM. The coming of age of liquid chromatography coupled to tandem mass spectrometry in the endocrinology laboratory. J Chromatogr B Analyt Technol Biomed Life Sci 2012; 883-884: 50-58, doi: 10.1016/j.jchromb.2011.08.027.

21. Hu JB, Gu HC, Ding ZS, Yao L, Fan YS, Ding XH. [Study on intervention effect of Jieduquyuziyin prescription systemic lupus erythematosus by HPLC-Q-TOF/MS]. Zhongguo Zhong Yao Za Zhi 2013; 38: 3747-3752.

22. Altman R, Asch E, Bloch D, Bole G, Borenstein D, Brandt K et al. Development of criteria for the classification and reporting of osteoarthritis. Classification of osteoarthritis of the knee. Diagnostic and Therapeutic Criteria Committee of the American Rheumatism Association. Arthritis Rheum 
1986; 29: 1039-1049, doi: 10.1002/art.1780290816.

23. Lachance L, Sowers MF, Jamadar D, Hochberg M. The natural history of emergent osteoarthritis of the knee in women. Osteoarthritis Cartilage 2002; 10: 849-854, doi: 10.1053/joca.2002.0840.

24. Cecil RL, Archer BH. Arthritis of the menopause. J Am Med Assoc 1925; 84: 75-79, doi: 10.1001/jama.1925.0266028000 1001.

25. Wluka AE, Cicuttini FM, Spector TD. Menopause, oestrogens and arthritis. Maturitas 2000; 35: 183-199, doi: 10.1016/S0378-5122(00)00118-3.

26. Ushiyama T, Ueyama H, Inoue K, Ohkubo I, Hukuda S. Expression of genes for estrogen receptors alpha and beta in human articular chondrocytes. Osteoarthritis Cartilage 1999; 7: 560-566, doi: 10.1053/joca.1999.0260.

27. Lee JS, Ettinger B, Stanczyk FZ, Vittinghoff E, Hanes V, Cauley JA, et al. Comparison of methods to measure low serum estradiol levels in postmenopausal women. J Clin Endocrinol Metab 2006; 91: 3791-3797, doi: 10.1210/jc.20052378.

28. Stanczyk FZ, Jurow J, Hsing AW. Limitations of direct immunoassays for measuring circulating estradiol levels in postmenopausal women and men in epidemiologic studies. Cancer Epidemiol Biomarkers Prev 2010; 19: 903-906, doi: 10.1158/1055-9965.EPI-10-0081.

29. Yang DT, Owen WE, Ramsay CS, Xie H, Roberts WL. Performance characteristics of eight estradiol immunoassays. Am J Clin Pathol 2004; 122: 332-337, doi: 10.1309/ 5N2R4HT4GMOAGPBY

30. Jaque J, Macdonald H, Brueggmann D, Patel SK, Azen C, Clarke $\mathrm{N}$, et al. Deficiencies in immunoassay methods used to monitor serum Estradiol levels during aromatase inhibitor treatment in postmenopausal breast cancer patients. Springerplus 2013; 2: 5, doi: 10.1186/2193-1801-2-5.

31. Rosner W, Hankinson SE, Sluss PM, Vesper HW, Wierman ME. Challenges to the measurement of estradiol: an endocrine society position statement. J Clin Endocrinol
Metab 2013; 98: 1376-1387, doi: 10.1210/jc.2012-3780.

32. Stanczyk FZ, Clarke NJ. Advantages and challenges of mass spectrometry assays for steroid hormones. J Steroid Biochem Mol Biol 2010; 121: 491-495, doi: 10.1016/j.jsbmb.2010.05 001

33. Krone N, Hughes BA, Lavery GG, Stewart PM, Arlt W Shackleton $\mathrm{CH}$. Gas chromatography/mass spectrometry (GC/MS) remains a pre-eminent discovery tool in clinical steroid investigations even in the era of fast liquid chromatography tandem mass spectrometry (LC/MS/MS). J Steroid Biochem Mol Biol 2010; 121: 496-504, doi: 10.1016/j.jsbmb. 2010.04.010.

34. Kushnir MM, Rockwood AL, Roberts WL, Yue B, Bergquist J, Meikle AW. Liquid chromatography tandem mass spectrometry for analysis of steroids in clinical laboratories. Clin Biochem 2011; 44: 77-88, doi: 10.1016/j.clinbiochem.2010. 07.008.

35. Santen RJ, Demers L, Ohorodnik S, Settlage J, Langecker $\mathrm{P}$, Blanchett $\mathrm{D}$, et al. Superiority of gas chromatography/ tandem mass spectrometry assay (GC/MS/MS) for estradiol for monitoring of aromatase inhibitor therapy. Steroids 2007; 72: 666-671, doi: 10.1016/j.steroids.2007.05.003.

36. Rocha MJ, Cruzeiro C, Rocha E. Development and validation of a GC-MS method for the evaluation of 17 endocrine disruptor compounds, including phytoestrogens and sitosterol, in coastal waters - their spatial and seasonal levels in Porto costal region (Portugal). J Water Health 2013; 11: 281296, doi: 10.2166/wh.2013.021.

37. Twaddle NC, Churchwell MI, Newbold RR, Delclos KB, Doerge DR. Determination using liquid-chromatographyelectrospray tandem mass spectroscopy of ethinylestradiol serum pharmacokinetics in adult Sprague-Dawley rats. $J$ Chromatogr B Analyt Technol Biomed Life Sci 2003; 793: 309-315, doi: 10.1016/S1570-0232(03)00331-3.

38. Aizawa Y. [Double isotope method - with special reference to estrogen (sulfonylating reagent $35 \mathrm{~S}$ method)]. Nihon Rinsho 1971; 29: 1267-1272. 